\title{
Degradation of Geoecological and Hydrological Conditions due to Grazing in South Carpathian Mountains under the Influence of Changing Social Structure in Romania
}

\author{
URUSHIBARA-YOSHINO Kazuko* and MORI Kazuki** \\ * Department of Geography, Hosei University, Chiyoda-ku, Tokyo 102-8160, Japan \\ ** Department of Geosystem Sciences, Nihon University, Setagaya-ku, Tokyo 156-8550, Japan
}

\begin{abstract}
This study tried to clarify the ecological damage in the areas of sheep transhumance, after the regime change of 1989, in the South Carpathian Mts. of Romania. The number of sheep increased by a factor of ten per hectare in areas where transhumance was practiced in the South Carpathian Mountains. This was because the sheep cheese produced in this area became more popular and increased in price. Jina and Poiana Sibiului villages are located on the third peneplain (900-1000 m a.s.l.) of the Southern Carpathian Mountains, which consists of crystalline schist of Precambrian origin. Soil erosion of common lands and water pollution caused by the transhumance of sheep is a serious problem in these villages. Soil erosion speeds were measured by comparing profiles on Sept. 20, 2003, and Sept. 6, 2004. Soil erosion in these transhumance areas progressed more during that one year. The bedrock is extremely hard and the recovery of soil and vegetation will probably be difficult over the short term. In Pătârlagele, where soils were composed of Miocene marl, soil erosion was very prevalent and easily progressed. However, the recovery of soils and vegetation was faster than in Jina and Poiana Sibiului, because of the softer and younger mother rock. In Jina and Poiana Sibiului, the Roma and Bayash people have been washing wool in the creeks. The water was seriously polluted as a result. Results of a chemical analysis showed high sodium, potassium and bicarbonate levels after wool washing. It is recommended that in areas with soil erosion, sheep would not be allowed entry so as to protect nature. Wool washing should be done in plants, where polluted water can be treated before being discharged into natural.
\end{abstract}

Key words: Romania, transhumance of sheep, soil erosion, water pollution, peneplain, land degradation

\section{Introduction}

In order to investigate the issues of land degradation, soil erosion, water pollution and other geoecological variables after the 1989 regime change in Romania, a cooperative study was initiated by a group of Japanese and Romanian geographers.

Peoples in the rural areas are now recovering from the mood of pessimism that followed 1989, but the geoecological conditions of the countryside in the mountain regions are not always in good order. The present study will seek to clarify the conditions from the standpoint of geo- morphology, hydrology and human geography and finally, to give advice on the reduction of the present ecological damage and for the establishment of more favorable methods of land use, water use, grazing and other human activities.

\section{Study Regions}

\section{Geographical conditions and social economical conditions}

The area of Romania is $237,500 \mathrm{~km}^{2}$ and its population is 22.5 million in 1998 (Balteanu 2003). Nearly $80 \%$ of the working population is engaged in agriculture and forestry. Romania is generally divided into three main regions (Bog- 


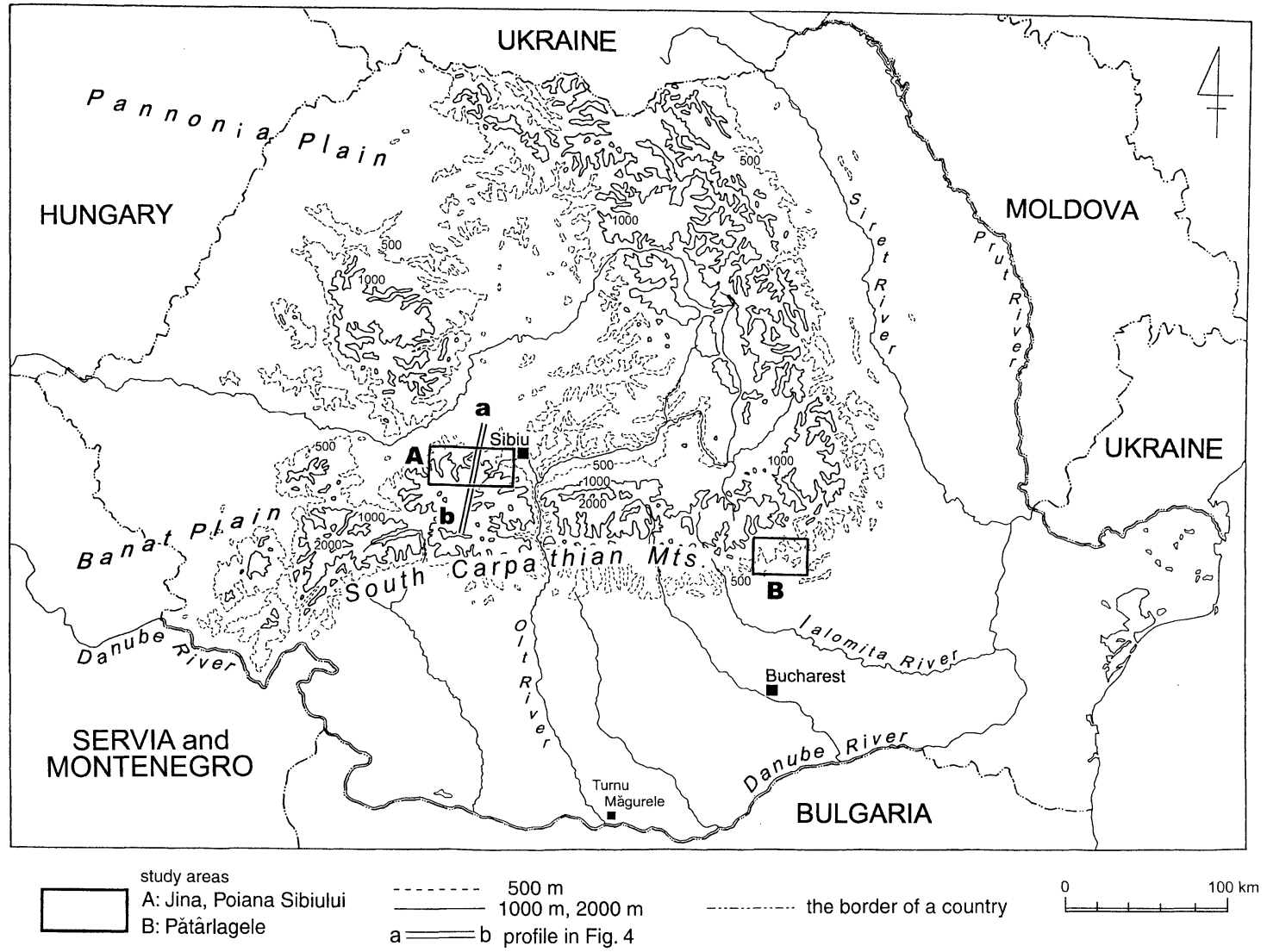

Figure 1. Geographical sketch of the topography of Romania and the study area.

dan et al. 2004): (1) The Central Mountains; (2) The Danube Plains of Wallachia and Moldavia; and (3) Transylvania and Banat. The mountains are divided into three ranges. Namely, these are the Eastern Carpathians, Southern Carpathians and Western Carpathians (Apcen Mountains) (Balteanu 2006).

The present study areas are in the South Carpathian Mountains. The location of the study areas is shown in Figure 1 as Regions A and B. In Region $\mathrm{A}$, our research fields are Jina and Poiana Sibiului, located on the north facing slopes of the Cindrel Mountains, the central part of the South Carpathian Mountains. The Cindrel Mountains are thickly forested with beach and oak trees at lower elevations and pines and other conifers at higher elevations. But the upper, ridge parts of the mountains are covered by grassland, which are used for transhumance. As Region B, Pătârlagele, the eastern part of the South Carpathian Mountains, is chosen based on the following geological differences.

Geological map which is compiled from the map of Academia Republicii Socialiste România (1979) is shown in Figure 2. This map shows that some part of the South Carpathian Mountains is composed by the materials of Precambrian crystalline schist exceptionally. The other areas are mainly Mesozoic and Tertiary materials as normal Alps Mountains. Therefore study areas were chosen from 2 places. Region A was chosen from typical Precambrian crystalline schist, and the other shown as B is from Tertiary sedimentary rock areas. A locates in Cindrel Mountains where are composed of Precambrian crystalline schist and peneplains landform. Region B locates in the Tertiary sedimentary rock area and landslides are very popular.

After the revolution in 1989, the agricultural lands were given back to the past owners or their descendents, as far as this could be established by the old documents of title, but not all the 


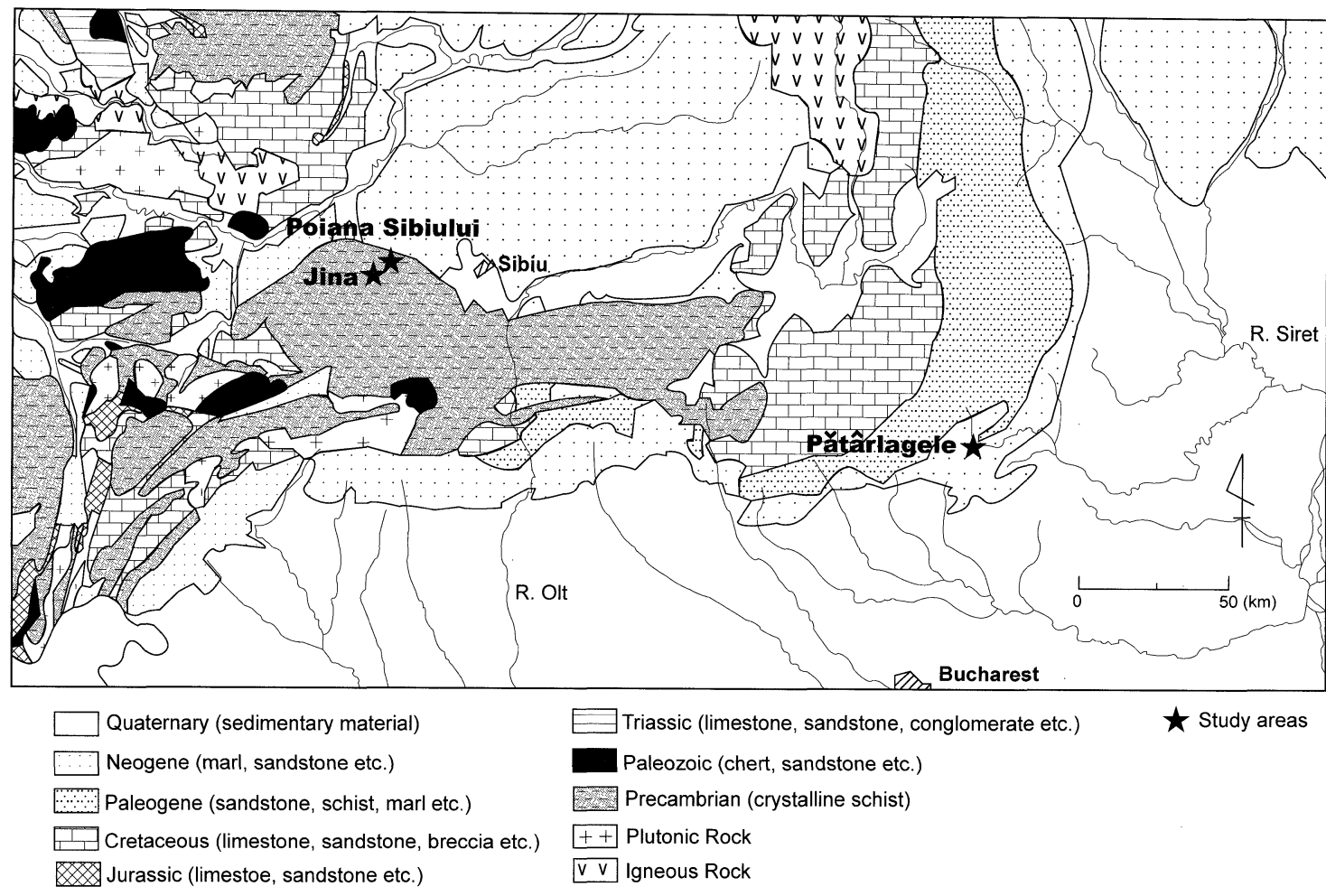

Figure 2. Geological map of South Carpathian Mountains.

owners actually farm the land at the present time. In such cases, they rent the fields to farmers and at the present time, the land is badly worked in some instances. This has resulted in land degradation, even though this region is located in the fertile, broad Chernozem zone. Due to the underdeveloped transport system, agricultural products do not always reach national or international markets. Also, the farmers are not willing to establish an Agricultural COOP.

In 2002, when one of the writer visited Jina and Poiana Sibiului, a base area for transhumance, serious soil erosion had already started on the marginal parts of the pasture land. Near Poiana Sibiului, a Roma settlement had already expanded into the area of the village. During our study in this area in 2003 and 2004, the Roma settlement expanded with great speed. They used common lands freely for washing and drying wool.

\section{Study areas regarding soil erosion and water pollution}

Cindrel Mountains The problems of soil erosion and water pollution have been studied taking an example in the Cindrel Mountains, which forms one part of the Carpathian Mountains bending westwards.

Study areas are shown in Figures 1, 2 and 3. The location of profile taken in Figure 4 are shown also in Figure 1. The central part the South Carpathian Mountains is formed mainly from the Mesozoic limestone and sandstone, but Tertiary conglomerate and sandstone are also found in the fringe areas. In the central part of the region Precambrian crystalline schist has intruded as a block. The study objects were chosen taking into consideration the vertical cross sections of the peneplains with their geological conditions and vegetation zones shown in Figure 4.

The Precambrian crystalline schist is dominant in the Cindrel Mountains (Buza and Fesci 1983). There are three peneplains: Step I, about 2000$2200 \mathrm{~m}$ (equivalent to the highest altitudes) (the Borascu Peneplain); Step II, about $1800 \mathrm{~m}$ (the Raul Ses Peneplain), and; Step III, about 950$1100 \mathrm{~m}$ (the Gornovita Peneplain). Settlements like Jina and Poiana Sibiului are located on Step 


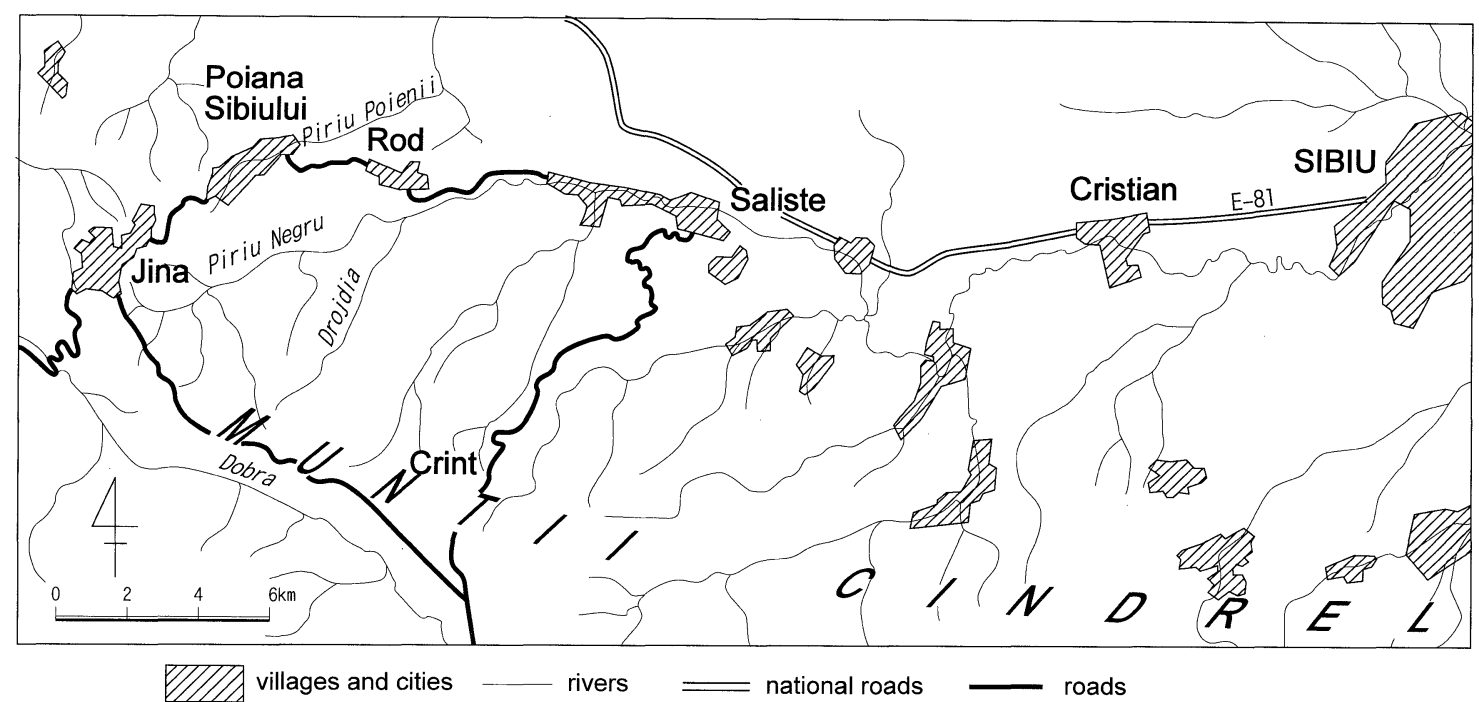

Figure 3. Detail map of A region in Figure 1.

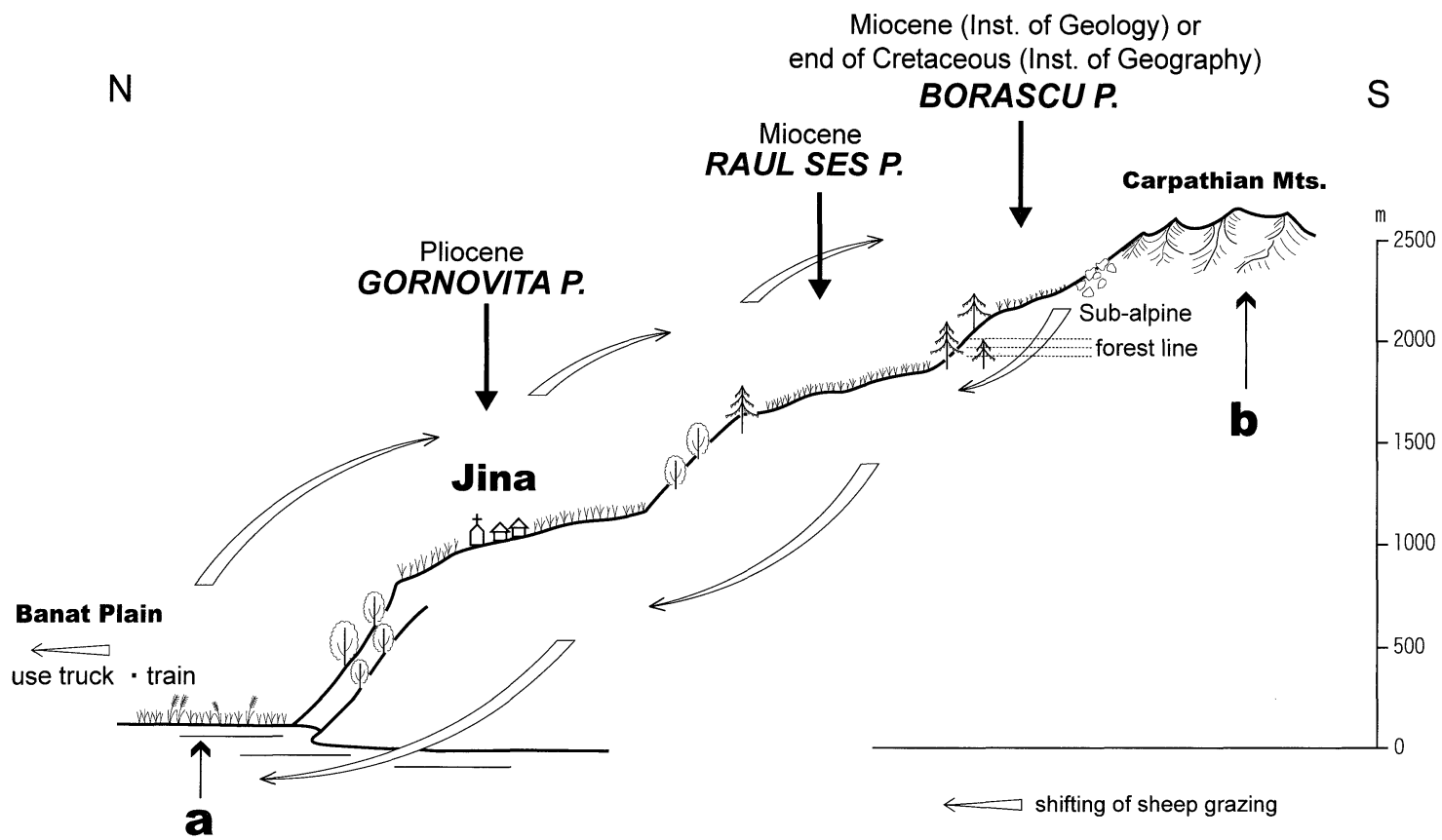

Figure 4. Peneplains and vegetation zones on a cross section of the Cindrel Mountains.

III, where our observations were made. These settlements are all based on transhumance. The farmers and their stock all shift in spring from Step III to Step II and stay on Step I in summer. After coming back to the base settlements in autumn, sheep move further away to the lowlands of the Banat Plain, where they stay in winter (Uruhibara-Yoshino and Hada 2005; Urushibara-
Yoshino 2006). Sheep grazing stays Banat Plain during winter time. In spring, sheep shift up to higher places and shift back to lower places in autumn. Namely, sheep stay from 1 May to 10 May on the Peneplain of Gornovita, from 10 May to 15 June on the Raul Ses Peneplain, from 15 June to 1 Sept. on the top of South Carpathian Mountains. Then sheep will shift back from 10 
Sept. to 1 Oct on the Raul Ses Peneplain, and from 1 Oct, to 14 Oct, on Gornovita Peneplain. Sheep will be transferred to Banat Plain, where they stay during winter by truck, train or walk.

Taking into account the fact that $38 \%$ $(1,075 \mathrm{~km})$ of the total length $(2,857 \mathrm{~km})$ of the Danube River passes through Romania or forms its border, this particular river has great importance to the country not only for water resources but also from an environmental point of view (Bogdan et al., 2004; Lennox 1996). The study area is located on the northern slope of the Southern Carpathians, and contains a tributary of the Olt River, which flows into the Danube at a point near the city of Turnu Magurele (Figure 1), after being regulated by approximately 30 reservoirs (Mandrut 2000; Whitehead and Noe 1995).

Observations were conducted in the comparatively small watershed, situated in the headwater basin of the Cibin and Saliste Rivers. The Saliste River, which springs from the vicinity of Jina, flows $26 \mathrm{~km}$ through the pastoral settlements of Rod, Tilisca, Gales and Saliste si Sacal, and runs into the Cibin and Orlat Rivers. Its drainage basin $\left(115 \mathrm{~km}^{2}\right)$ extends from west to east, the highest altitude being $950-1,100 \mathrm{~m}$ in the watershed at the western extremity, and ca. $500 \mathrm{~m}$ at its confluence with the Cibin River. In this area, the watershed is predominantly covered by pasture, which is used by local people as grazing land for sheep (Buza and Fesci 1983). The rural settlement of Jina, located on a mountain ridge, has a population of 4,200 and about 39,000 head of sheep in 2004. According to the results of inquiry at the village office, it is said that the number of sheep had increased tenfold as compared with the years before 1990. The drainage basin has a mean annual precipitation of approximately $640 \mathrm{~mm}$ (Urushibara-Yoshino 2005; UrushibaraYoshino and Hada 2005). Local people in the community depend on groundwater for drinking and rain water for washing.

Pătârlagele in the Musel Valley The land in the region near Pătârlagele, where Tertiary sedimentary rocks are distributed adjacent to Mesozoic sedimentary rocks, has been utilized partly by collective farm orchards cultivating plums, and partly for the transhumance of sheep. Before the time of the revolution, Balteanu (1983) studied this region and one of the pho- tographs taken by him shows serious soil erosion. In the present study, a southeast facing slope of the Virful Colane, near Muscel village, was taken as an example of a common grassland, where transhumance was practiced.

\section{Study Method and Results}

\section{Soil erosion}

Methods and materials 1) Type of soil erosion in study areas. The types of soil erosion, observed in the grasslands with transhumance on the north facing slope of Cindrel Mountains (Region A) and the south facing slope of Pătârlagele (Region B), are classified into Types I to IV, as shown in Figure 5. The progressive degree is expressed as (1) to (4). In Type I, not only sheep, but also heavy animals like cattle or horses are grazed together in the area. Here ample, thick soil layers can be found. In Type II, erosion occurs initially on steep slopes, but barren sites appear due to trampling by livestock, then this spreads along the slopes, where drainage also facilitates it. This trigger results in a series of connected chains from the upper part to the lower part of the slope, like a form of gully erosion. In the developed stage, the depth may reach 15-20 $m$ with a width of $20-50 \mathrm{~m}$ in extreme cases. In the case of gully erosion, even though there are differences in size, relatively large gullies develop on steep slopes with thick soil layers. However, the downward progression of erosion stops, when bare rocks appear in the gully bottom. Type III is also found on grazing terraces. This happens of when many flocks of sheep continuously tread along the gentlest gradients of the slopes. Tracks develop in accordance with the frequency with which the sheep are moved. Here road-like steps are also formed by the movement of large, heavy cows. When heavy rainfall comes, the soil on parts of the terraces will be washed out and the terrace will become part of the drainage channel. In the most advanced cases of Type III erosion, the soil is completely removed and bare rocks are exposed. Furthermore, as the sheep, cattle and horses use parts of the terraces continuously, the remaining soil will fall down to the lower parts of the slope, exposing bare rocks. In Type IV, the slopes are steeper than those of the surrounding mountain 


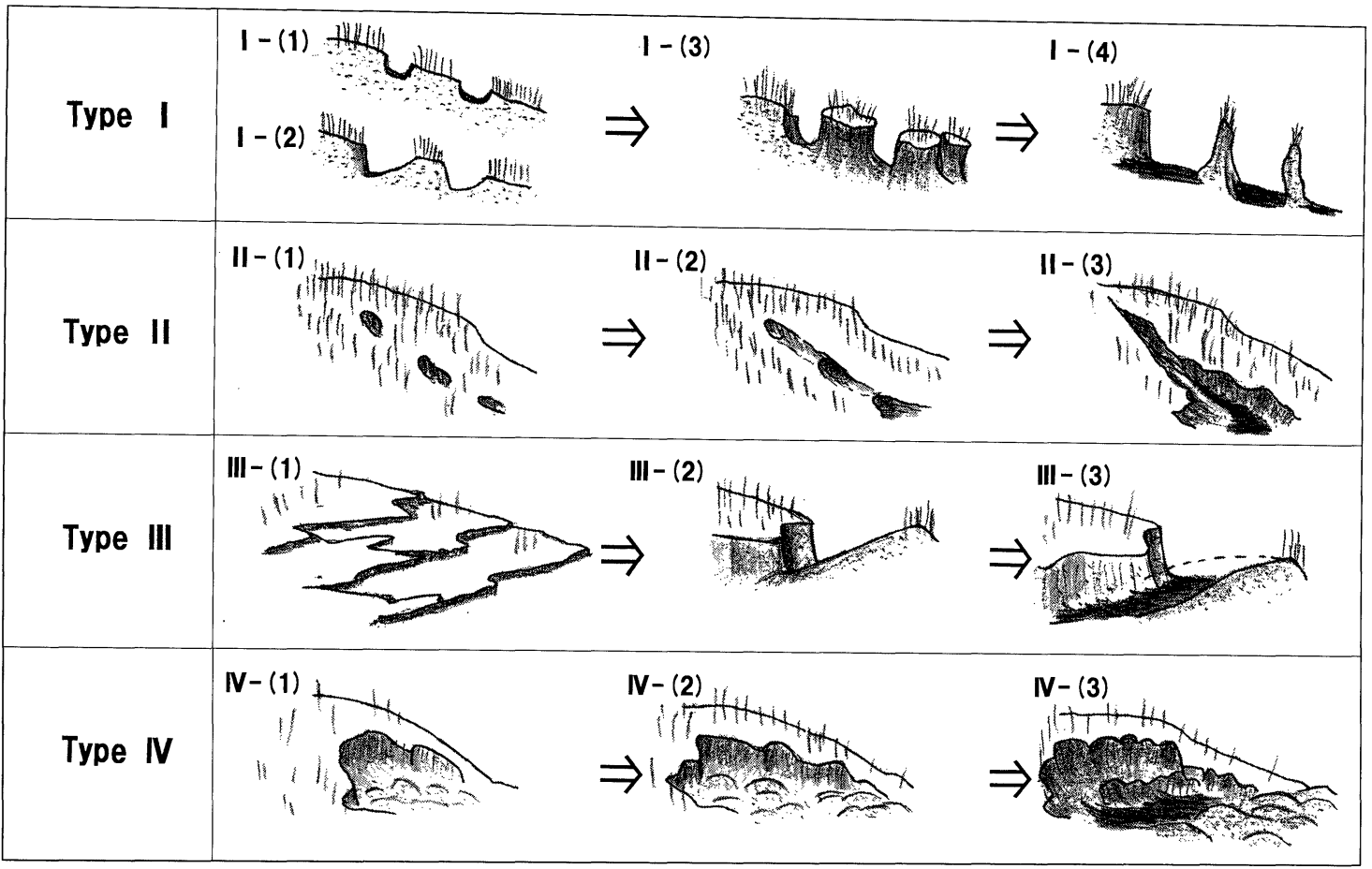

Figure 5. Classification of soil erosion in South Carpathian Mountains.

areas, and cases of erosion have been caused not only by sheep, but also by human movement that is part of the transhumance process. In the southern parts of the Carpathian Mountains, the type of rocks determines the occurrence. In particular, in the case of crystalline schist, they were observed to they develop according to angle of the slope.

The erosion develops and spreads on the ground surface in the upstream direction. The soil layer is thin on the steep slopes of the crystalline schist area, so the bedrock tends to appear. When the erosion reaches the bedrock, it becomes hard to regenerate the vegetation cover, resulting in the rock being exposed for a long period of time. However, in the case of areas with thick weathered layers of Tertiary rock, the erosion sites evolve into being like the land slide areas.

2) Speed of soil erosion. The profiles of soil erosion areas were measured on Sept. 20, 2003, and again on Sept. 6, 2004. Both profiles were compared and the differences were considered to indicate the speed of soil erosion.

3) Rain gauge measurement. Precipitation data could not obtained in the study area. To monitor climatic conditions in the study area, rain gauge was set in Jina. A rain gauge (Type: 34-T, KADEC 21-MIZU-C) was set at Jina, $988 \mathrm{~m}$ a.s.l.

Figure 6 shows the observation station set in a grassland field in Poiana Sibiului on the Gornovita Peneplain, which is the third peneplain. Precipitation records were taken from Sept. 19, 2003 to Jul. 15, 2005. The daily precipitation expressed by the vertical bar is shown in Figure 7. Seasonal changes of precipitation were clear: relatively large amounts occurred from April to October, the warmer season, with the maximum from May to September. The dry season is from November to March. Rainfall occurs continuously with short interruptions from April to October. Our measurements of precipitation can be used to consider the climatic conditions that affect soil erosion. This applies especially to the frequency and intensity of rainfall. Even the annual precipitation at this location is about $600 \mathrm{~mm} / \mathrm{year}$, and this intensive rain, especially the higher daily amounts, will cause severe land degradation. The occurrence of such heavy rain in semi-arid zones will especially affect the progress of soil erosion. 
Throughout the present observation period, it was found that daily rainfall of over $20 \mathrm{~mm} \mathrm{oc-}$ curred four times a year (eight times during the two years in seasons with heavy rain, as shown

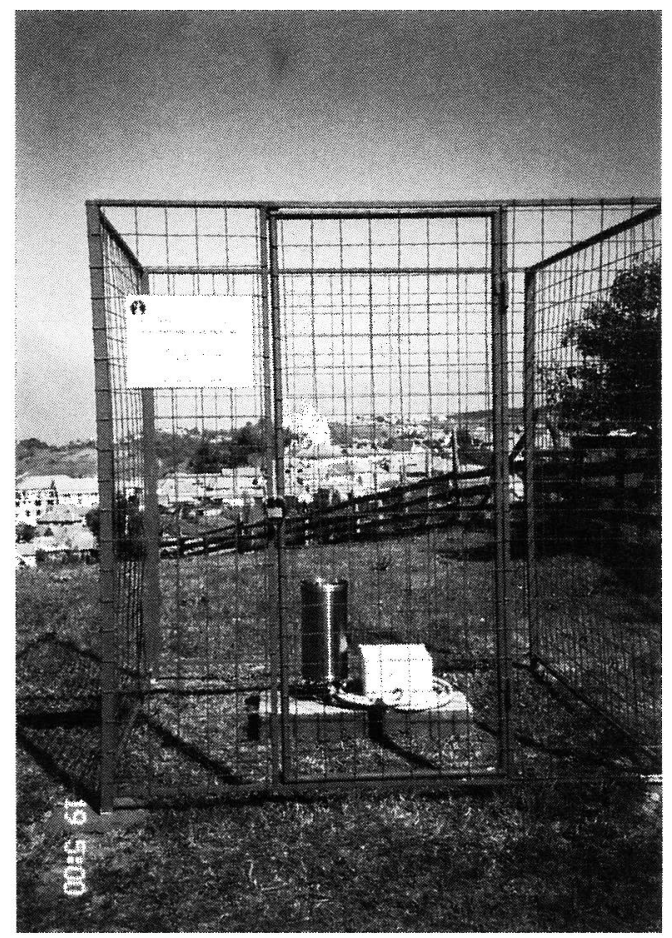

Figure 6. Rain gauge in Jina (taken by $\mathrm{K}$. Urushibara-Yoshino, Aug. 19, 2003). in Table 1). As a result of the heavy daily precipitation, total values are rather high. A maximum of $47 \mathrm{~mm}$ per day was recorded in two occasions. Under these conditions, once the soil layer on the surface is exposed, the heavy rains can expand the area affected by erosion very easily. This also leads to continuous exposure of the parent rock.

Climatic conditions for sheep transhumance were studied in Romania (Urushibara-Yoshino and Hada 2006). Because of the semi-arid conditions under which this occurs, the peneplain on the northern slopes has developed and maintains a grassland. According to our observations of precipitation, heavy rain occurs occasionally (eight times of the daily precipitation more than $20 \mathrm{~mm}$ ). This may accelerate erosion and further

Table 1. Daily precipitation occurrence in the period of 666 days, from Sept. 19, 2003 to July. 15, 2005

\begin{tabular}{cc}
\hline $\begin{array}{c}\text { Daily precipitation } \\
\text { (mm/day) }\end{array}$ & Occurrence \\
\hline More than 40 & 2 \\
More than 20 & 8 \\
More than 15 & 14 \\
More than 10 & 34 \\
More than 1 & 182 \\
No rain days & 484 \\
\hline
\end{tabular}

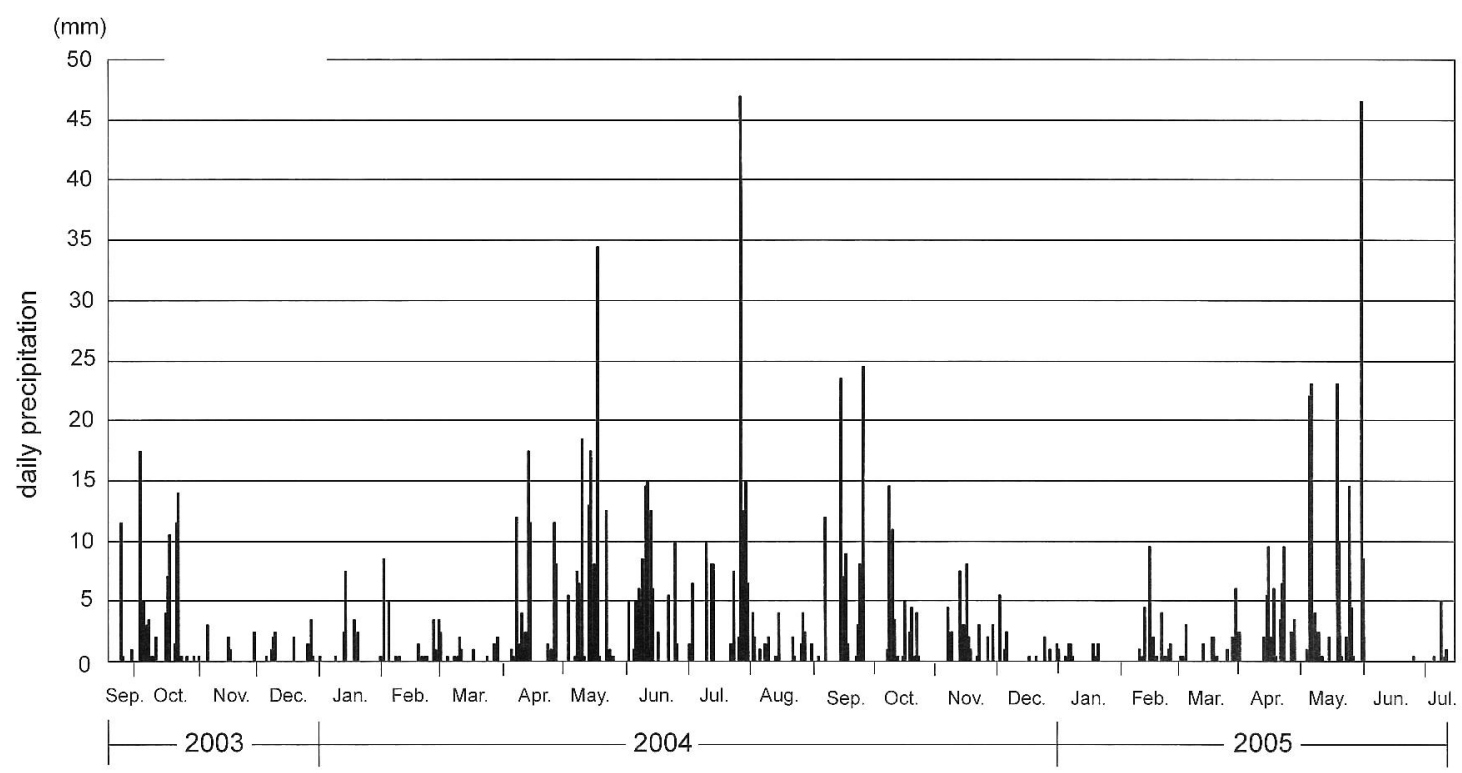

Figure 7. Daily precipitation in Jina (from Sept. 19, 2003, to Jul. 15, 2005). 
facilitate the development of land degradation before any chance of recovery can occur.

Soil erosion in Jina and Poiana Sibiului We investigated soil erosion that had occurred through the transhumance of sheep in the area surrounding Jina, one of the transhumance bases on the Step III peneplain. Because no large-scale maps were available for this area, it was impossible to draw a distribution map. However, the movement of material and the form of its displacement were studied through simple measurement.

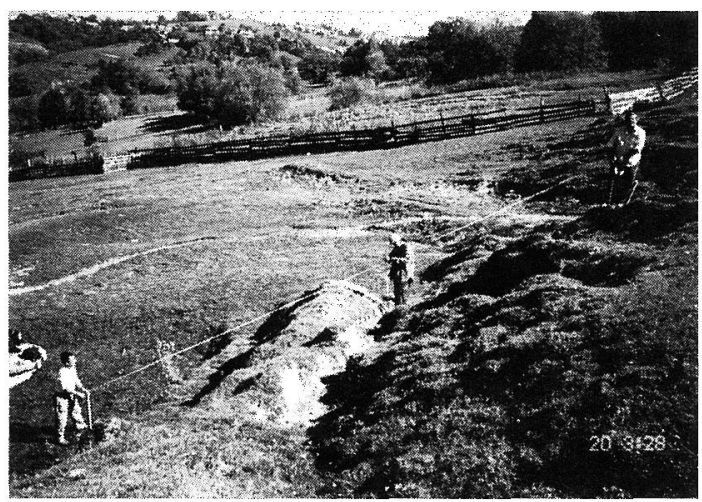

Figure 8. Measuring the slope at Dinuta Spring (taken by $\mathrm{K}$. Urushibara-Yoshino on Sept. 20, 2003)
1) Dinuta Spring for drinking water in Jina. In the study area there are springs and water holes with drinking water not only for sheep, cattle and horses, but also for the local people, who carry the water to their homes. The houses are distributed on the ridge, but the springs are located on the slopes at the head of the valley.

The types of soil erosion around these springs are a combination of Types I and III. The results of measurements carried out on September 20, 2003, are shown by broken line, and those taken on September 6, 2004, by a solid line (Figures 8 and 9). Lowering of the ground surface by soil erosion reached $70 \mathrm{~cm}$ at the maximum. The gully had already reached bedrock at that location (Type III with the status of III-(3)). Also, at a location with a steep slope (47 degrees), Type I erosion had reached the status of I-(3) or I-(4). Because they are sites where sheep, cattle and horses come frequently to drink water, erosion had reached the stage where crystalline schist had been exposed.

2) Gully type soil erosion in Poina Sibiului. This type appears on the border areas between Jina and Poiana Sibiului where the grasslands are utilized cooperatively. At this location, a large instance is found of gully erosion crossing the main road connecting Jina to Poiana Sibiului. Mea-

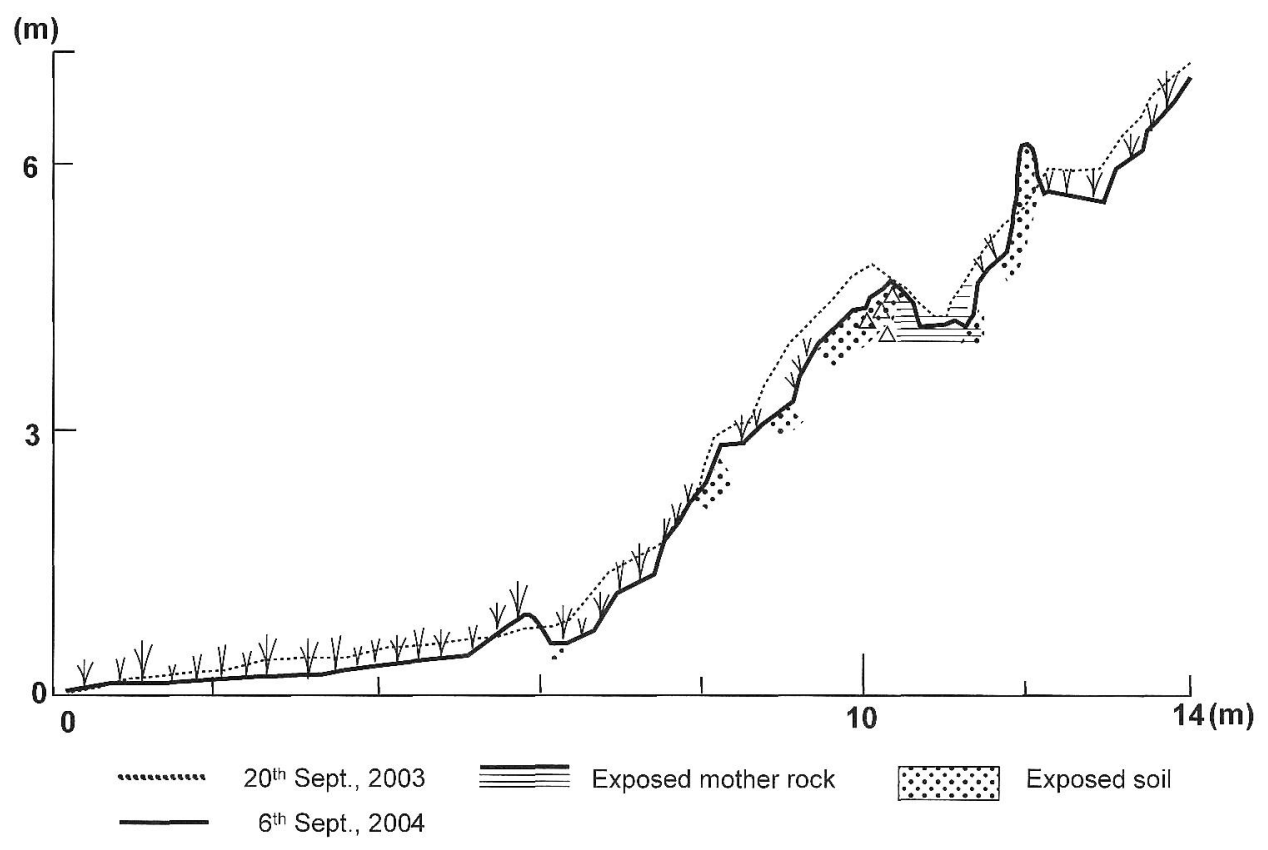

Figure 9. Cross section of the slope at Dinuta Spring in Jina. 
surement of this gully was made along a longitudinal section (Figure 10), and cross sections at three points (Figure 11). A comparison was made between the findings of September 20, 2003 (broken line), and September 5, 2004 (solid line).
As a result, it became clear that the slope at the valley head had retreated by about $1 \mathrm{~m}$. Retreat was also observed at several places forming knick points. When the slope retreat had reached this stage, it did not shift anymore. Along the cross sections, it was observed that

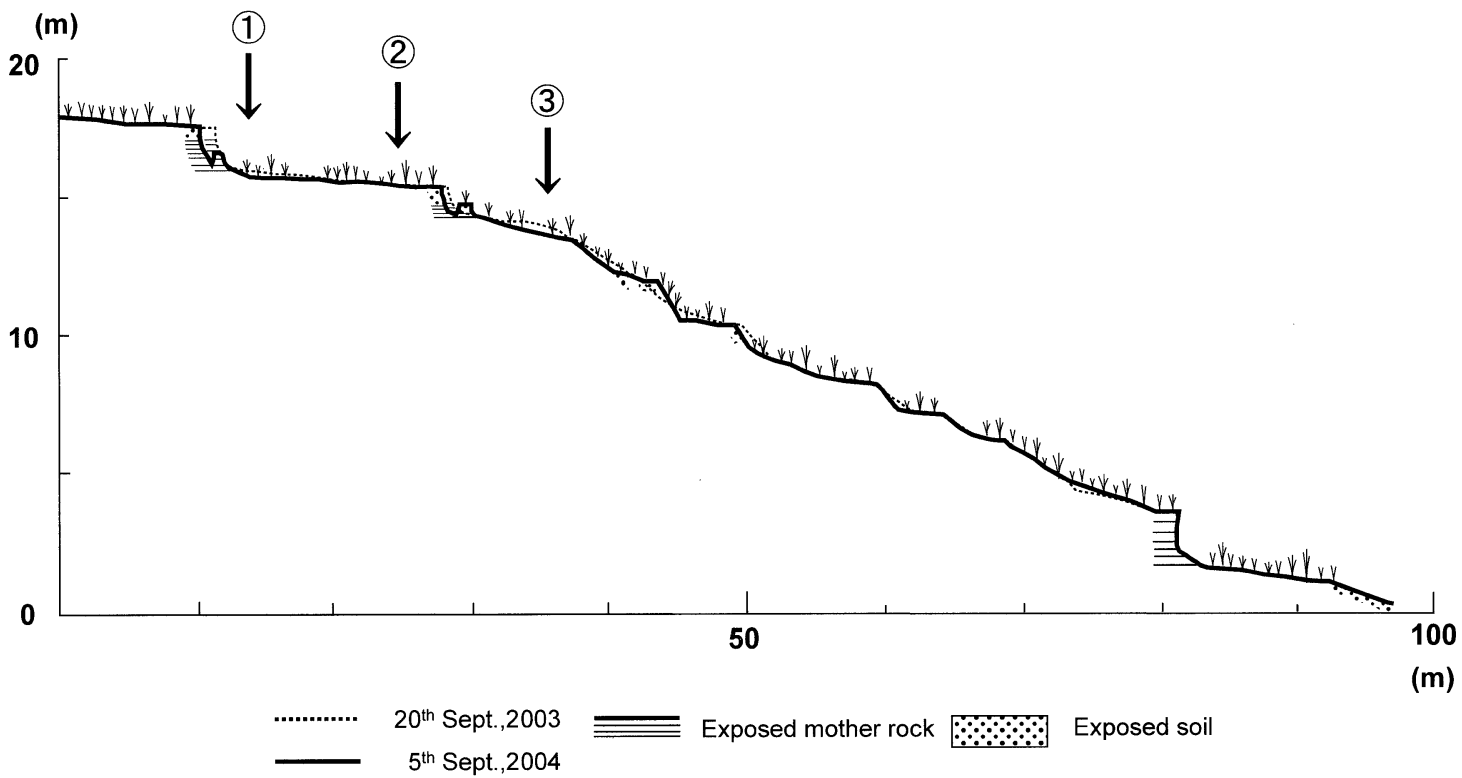

Figure 10. Longitudinal section of erosion gully in Poiana Sibiului.

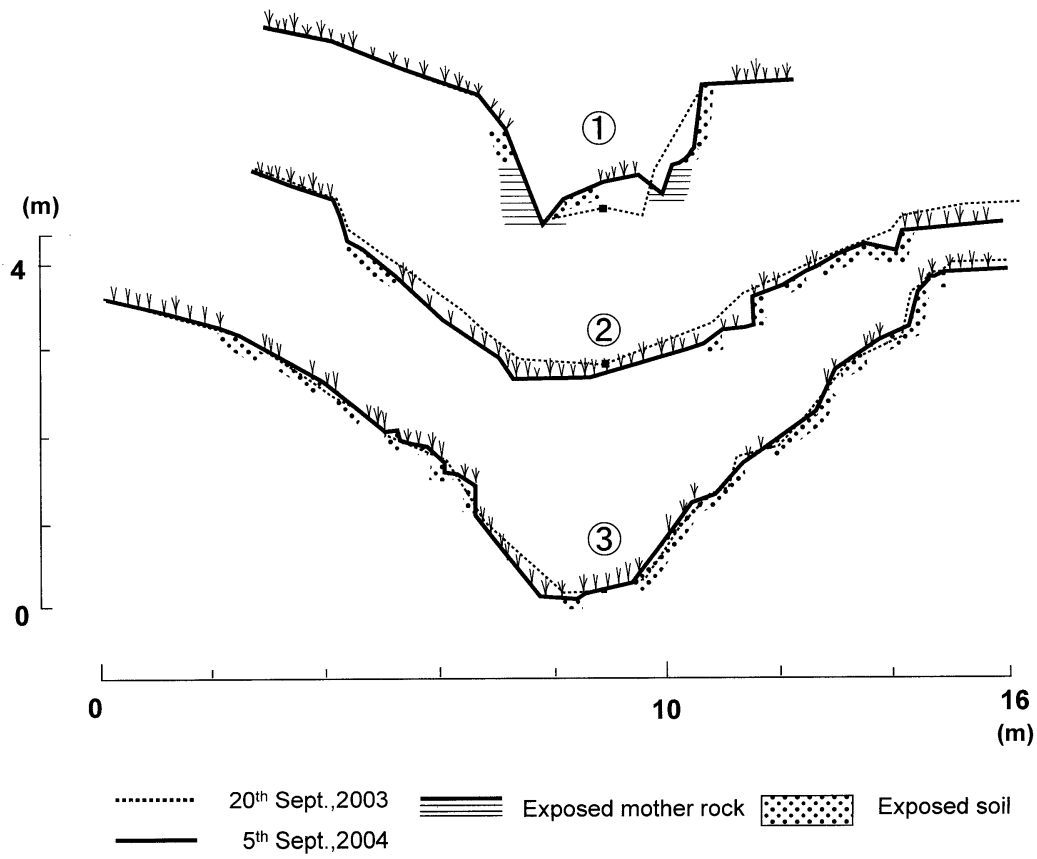

Figure 11. Cross sections (1)-(3) of erosion gully in Poiana Sibiului. 
the head parts of the gully on the side slopes had retreated and the eroded soil materials had shifted to the valley bottom. As observed at these points in the valley bottom, the amount of shifted material was large.

3) Community grasslands in Poiana Sibiului. The people dry shorn wool on the open grass terrain surrounding the settlement. It has become evident that the soil erosion on these relatively steep slopes has been broadly speaking enlarged.

Soil erosion of Type IV is found in this area. It has already reached the condition of Type IV-(3). That is, the bedrock is exposed. Because the bedrock is Precambrian crystalline schist, it is very hard and, therefore, it cannot be expected that the soil will recover over a broad area of this again through accumulation of weathered materials over the short term.

In September 2003 at the edge of the town of Poiana Sibiului, there were a lot of houses inhabited by the Roma. One year later, in September 2004, their number had increased markedly. Washed wool was seen drying on the ground surface of the grasslands, and then being graded by the Roma according to quality. Roma drivers engage in transportation by trucks but on the other hand, the Romanian people make and sale cheese. After the 1989 revolution resulted in a substantial increase of Roma population in this region.

In some instances, the Roma occupied the houses which had been abandoned by Romanian Germans, who had emigrated to Germany. In other cases, like the case of this village, they built their own homes illegally, working with cheap materials and poor construction techniques. On the lower parts of the slopes, there are sites with accumulated garbage, dumping grounds of useless wool, and other used as outdoor breeding places for pigs. In addition, people, sheep and cattle are frequently moving about there. All these factors have enlarged the extent of Type IV-(1) erosion.

The most pressing matters in this region are as follows: when the process of erosion reaches the bedrock, the recovery of vegetation will be impossible. In the areas with Precambrian crystalline schist, everything should be done to stop the process as soon as possible. This is because these are the most vulnerable parts of the study area. Also areas of Type IV-(3) erosion on the lower parts of the slopes should be kept as small as possible.

4) Distribution of soil erosion areas in Jina and Poiana Sibiului. A distribution map showing the data mentioned above will be included in future studies. Common findings in the study areas are: the grasslands and the cultivated land in private ownership are in general kept in good condition. The existence of fences plays an important part in achieving this. In those areas, there is no danger of soil erosion. In the cooperatively owned grasslands, however, the number of sheep has increased tenfold since the 1989 revolution, as made clear by Shirasaka (2006), one member of the study group.

As a result, the deterioration of the environment in the latter case is progressing at high speed. We therefore would recommend more emphasis on environmental education, especially in relation to the special problems of the Roma.

Soil erosion in Pătârlagele In the present study, a southeast facing slope of the Virful Colane, Muscel Village, was taken as an example of common grasslands where transhumance was carried on. As shown in Figures 12 and 13, distribution maps were drawn for every soil erosion type in the region. The top of the slope is at 590 $\mathrm{m}$ a.s.l. and bottom of the slope $390 \mathrm{~m}$ a.s.l. A cross section is also shown in Figure 14. According to Figure 15, the bedrocks is exposed in the case of slopes with a gradient of more than 45 degrees, and the erosion reaches IV-(2) for Type IV and I-(4) for Type I. In particular, the most seriously eroded slope has a gradient steeper than 45 degrees, exposing the bedrock. An example of Type I-(4) is shown in Figure 15. Land degradation has been progressing on the steep slopes, but because the bedrock is sandstone, it seems that the supply of weathered materials has been good, even though the vegetation has not yet recovered. In the case of slopes with a gradient of less than 20 degrees, there are some signs of landslides that frequently produce soil erosion of Types II and III.

However here the vegetation recovers fast and there are few serious problems. It should be mentioned, however, that one must build a fence surrounding the parts of the slopes steeper than 


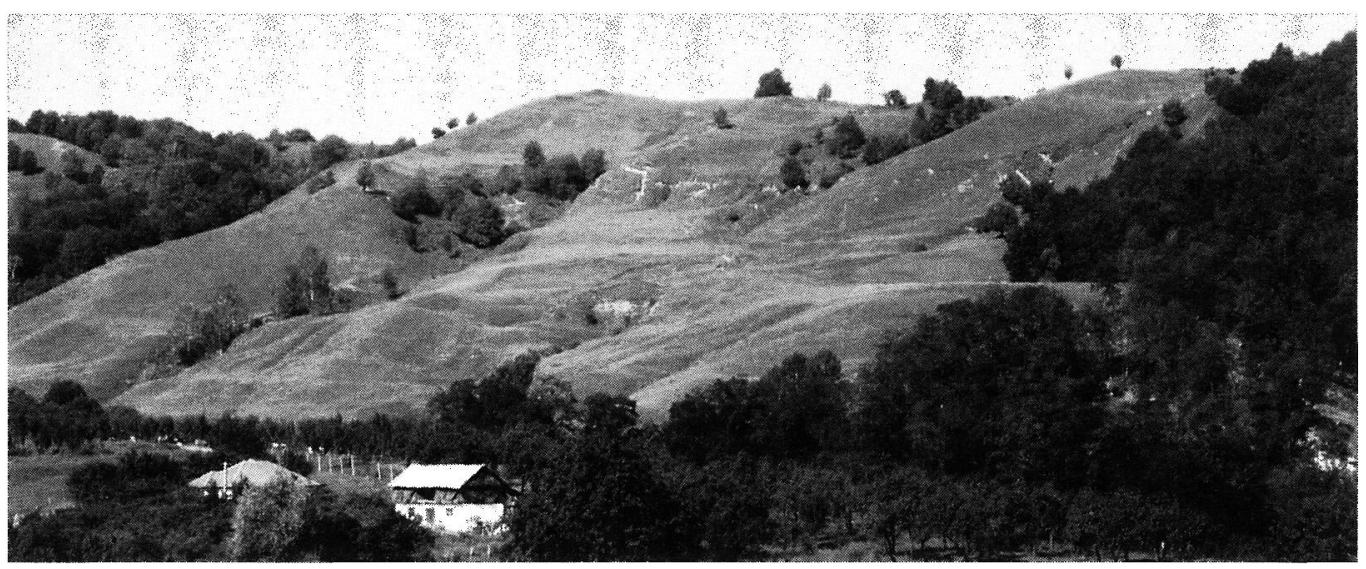

Figure 12. Soil erosion of common grasslands, Maloteasa Valley (taken by K. Urushibara-Yoshino, Sept. 1, 2004).
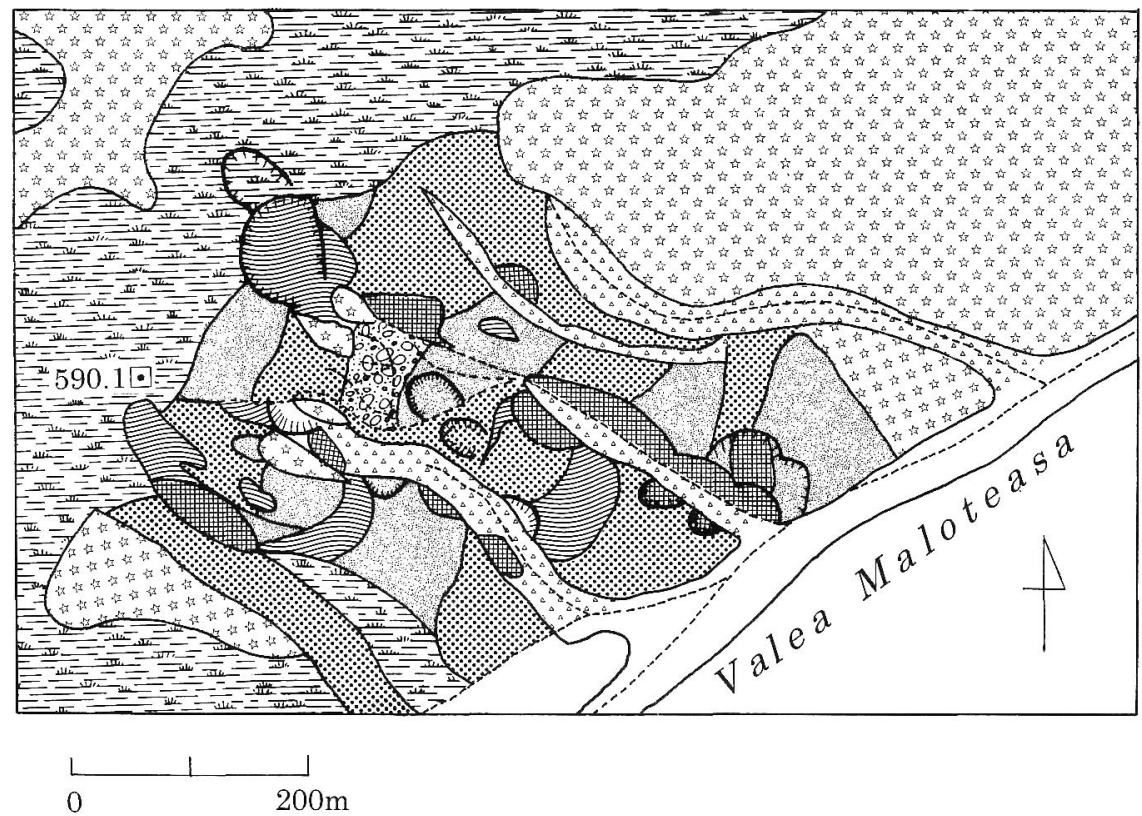

Figure 13. Distribution map of soil erosion types in the Maloteasa Valley, Muscel Village.

about 45 degrees, in order to prevent grazing by sheep and so facilitate the recovery of the vegetation.

1) Due to the severe soil erosion, exposed bedrock is widely seen in the region with Precambrian crystallized schist. Those regions are classified as Type II-(3) and Type IV-(3) by the present study. In these regions, the vegetation will not recover. It is also difficult to help its recovery without human intervention.
2) The regions with Tertiary sedimentary rocks have suffered from frequent land slide damage. In cases where the gradient of the slope is more than 45 degrees, the bedrock is exposed on the slopes.

\section{Water pollution}

A case of the Cibin River Hydrological investigations were conducted through August into September 2003 and again in August 2004 in the 


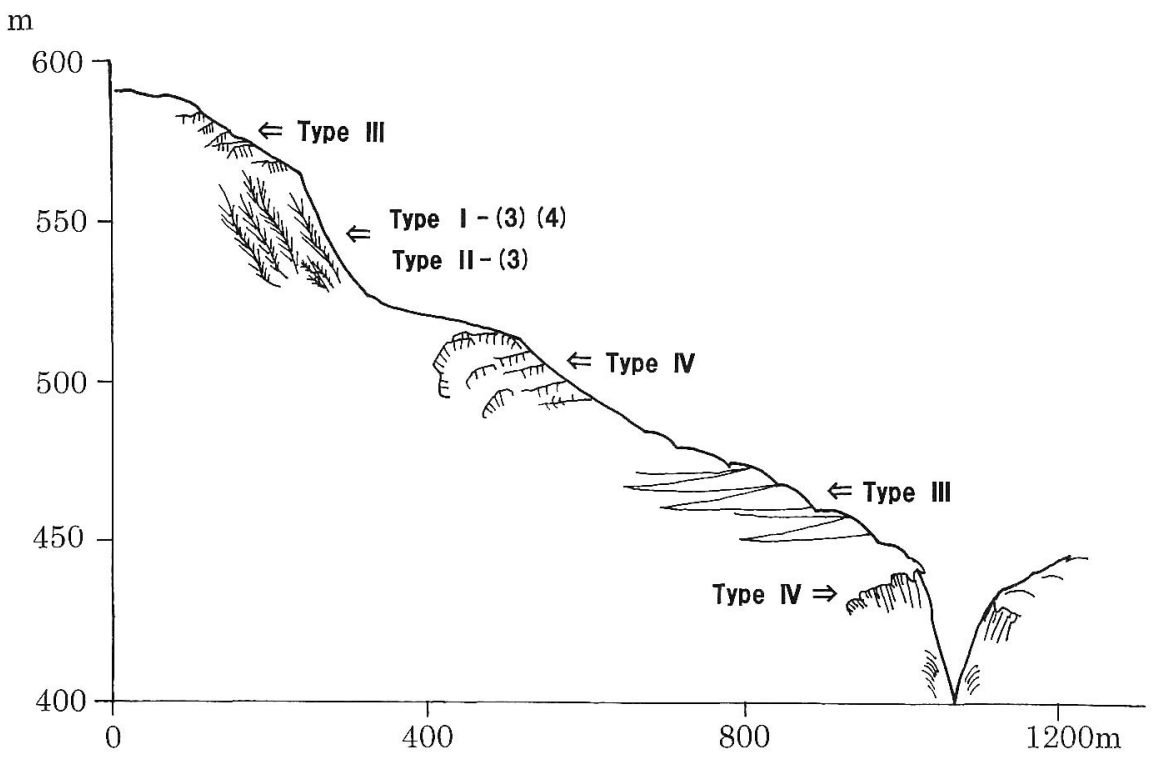

Figure 14. Cross section of a slope (NW-SE) of the Maloteasa Valley.

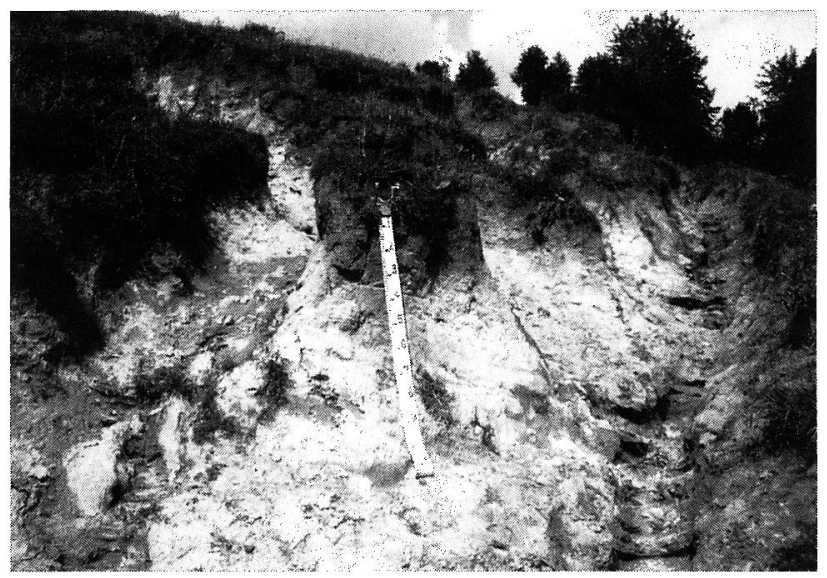

Figure 15. Soil erosion of common grassland, Maloteasa Valley (taken by K. Urushibara-Yoshino on Sept. 1 , 2004).

upper reaches of the Cibin River (Region A). Figure 16 shows a land-use map of the study area and the position of sampling sites. The quality of the river water including groundwater and stored rain water was assessed, using the following analytical methods.

Sodium, potassium, calcium, magnesium, chloride, sulphate, nitrate and ammonium were determined by ion chromatography. Bicarbonate analysis was based on titration with sulphuric acid. Chemical Oxygen Demand was obtained as consumption of potassium permanganate. In ad- dition to the analytical procedures for these chemical elements, the measurement of electrical conductivity was made in situ (Mori 2006; Mori et al. 2006).

A striking concentration of pollution in river water is observed at some particular points where sheared wool is washed directly in the river channel during the summer season. The local people and Roma wash sheared wool in the Cibin River (Figure 17). Contamination of river water by animal waste is also recognized at some observation points. Based on differences in con- 


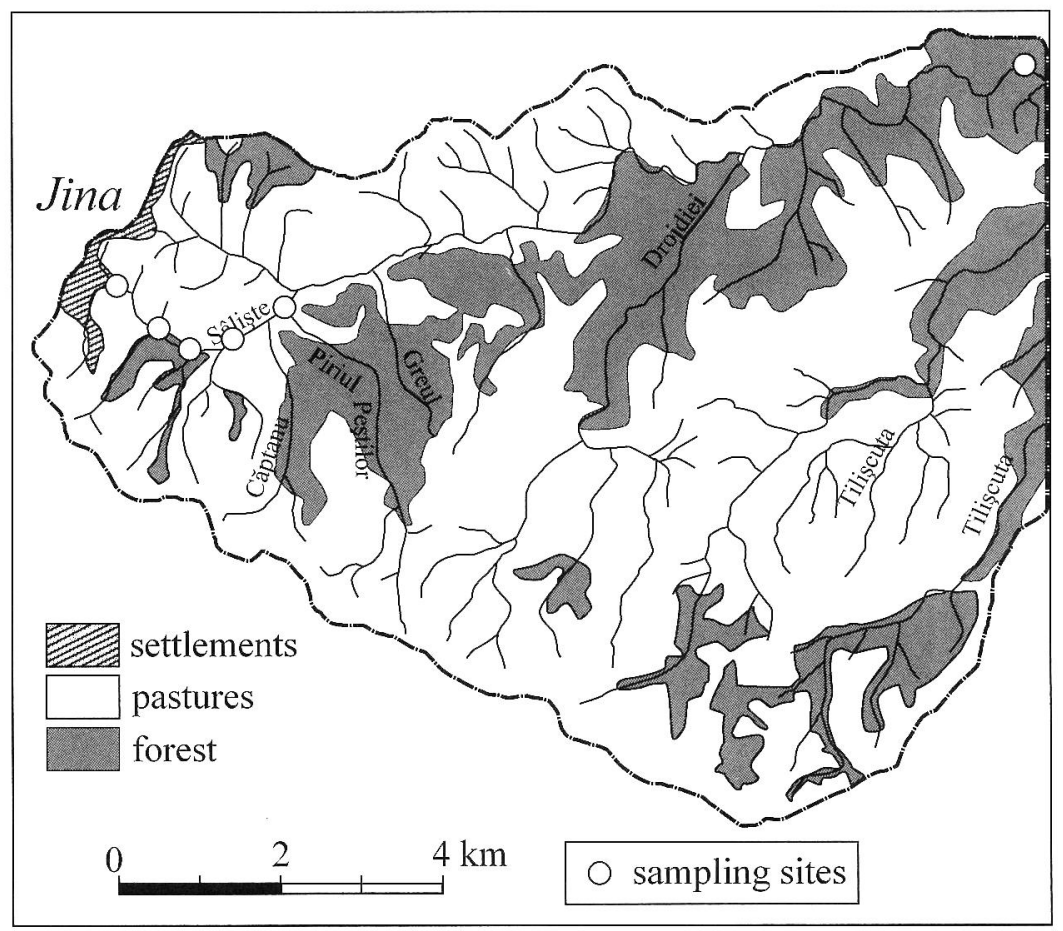

Figure 16. Land-use map of the headwater basin of the Cibin River and the locations of sampling sites.

centration and composition of major dissolved substances, a summary of the pollution of river water is shown in Figure 18. The controlled sample shows $215 \mu \mathrm{S} / \mathrm{cm}$ of electrical conductivity and $7.5 \mathrm{mg} / \mathrm{L}$ of $\mathrm{COD}$, which gives the background signature of the water in the study area to compare against the polluted samples to be compared (Figure 18). By contrast, the maximum values of pollutant concentrations in river water affected by wool washing include $8,960 \mu \mathrm{S} / \mathrm{cm}$ of electrical conductivity, $2,882 \mathrm{mg} / \mathrm{L}$ of COD, and $68.4 \mathrm{mg} / \mathrm{L}$ of ammonium ions. It is deducted that the enriched ammonium ions in the stream derive from sheep excrement which adheres to the fleece. The difference in electrical conductivity indicates whether the river water is affected by both domestic and stockbreeding sewage $(4,570 \mu \mathrm{S} / \mathrm{cm})$ or by stockbreeding sewage alone $(3,430 \mu \mathrm{S} / \mathrm{cm})$. The quality of the groundwater is much better than that of the river water, but pollution by animal waste is also recognised for spring water, with a maximum nitrate concentration of $21.0 \mathrm{mg} / \mathrm{L}$ (Mori 2005a, 2005b).

A Piper diagram permits the cation and anion

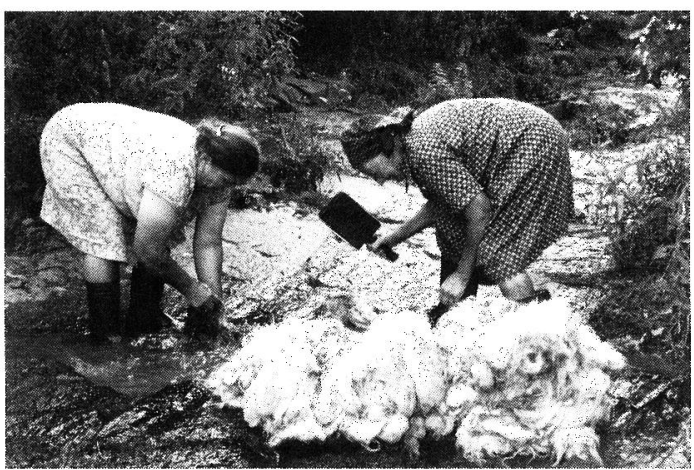

Figure 17. Local people washing sheared wool in the Cibin River (taken by K. Mori on Aug. 28, 2003).

compositions of many samples to be represented on a single graph in which major grouping or trends in the data can be discerned visually. As shown in the triangular and key diagrams of Figure 19 , types of water quality are designated according to the domain in which they occur on the diagram segments, and the hydrochemical faces of water are clearly classifiable into four categories as follows: rain water and river water 


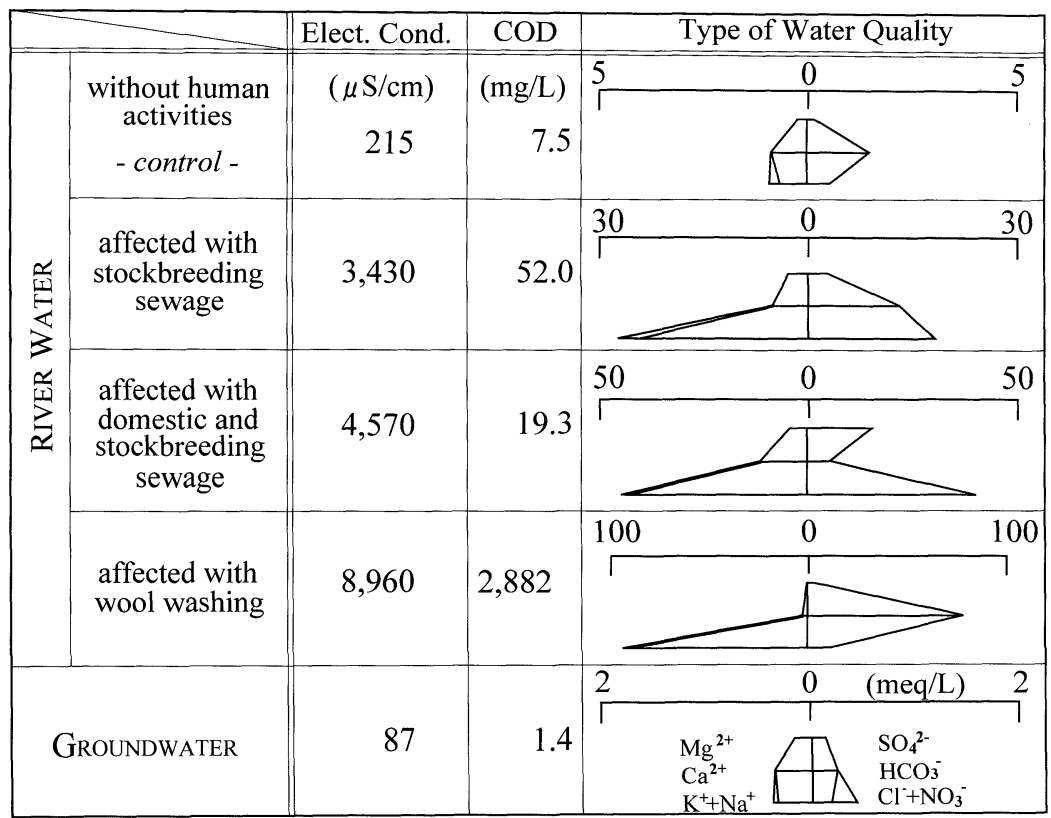

Figure 18. Summary of pollution of river water as classified by its primary factor.

without human activity as a control: $\mathrm{Ca}^{2+}-\mathrm{HCO}_{3}^{-}$, river water affected by domestic and stockbreeding sewage: $\mathrm{Na}^{+}-\mathrm{Cl}^{-}$, river water affected by wool washing: $\mathrm{K}^{+}-\mathrm{HCO}_{3}^{-}$, groundwater: $\mathrm{Na}^{+} / \mathrm{Ca}^{2+}-\mathrm{HCO}_{3}^{-}$with comparatively high levels of nitrate.

The distinguishing features of the water quality are consistent with the nature of both the land use and water use. The results show marked water pollution and a problem awaiting solution in order to sustain a better water environment. The water quality of the upper course of the Cibin River in central Romania was investigated with special reference to pollution and its cause. The characteristics of the river water quality were as follows:

i) Concentrations of dissolved substances show maximum values at the uppermost point, and decrease downstream as a result of dilution.

ii) Water is classified into four categories according to differences in concentration and composition of major dissolved substances.

a) As a transient phenomenon, striking contamination of the river water was found at some particular points during the summer season where sheared wool was washed directly in river channel. b) As a constant pollutant source, untreated domestic and stockbreeding sewage in rural areas has a strong effect on river water quality.

iii) The distinguishing features of river water quality were consistent with the nature of land use and water use as well.

iv) The results show conditions of marked water pollution and a problem awaiting solution in order to create and sustain a better water environment

A case of the Muscel River Hydrochemical characteristics on river water and phreatic groundwater in the Muscel River basin (Region B) were investigated with a research focus on their regional difference and primary cause. The Muscel River basin is located at 96 kilometer's distance in the northern direction of Bucharest, and has a total area of approximately $21 \mathrm{~km}^{2}$ with a length of about $8.8 \mathrm{~km}$. As is inferred from the fact that improvement of the sewage system is overdue in the study area, it is expected that the domestic wastewater from settlements has a considerable effect upon the quality of river and groundwater as a pollutant source. On this supposition, river water quality was preponderantly clarified as to the connection with groundwater. 


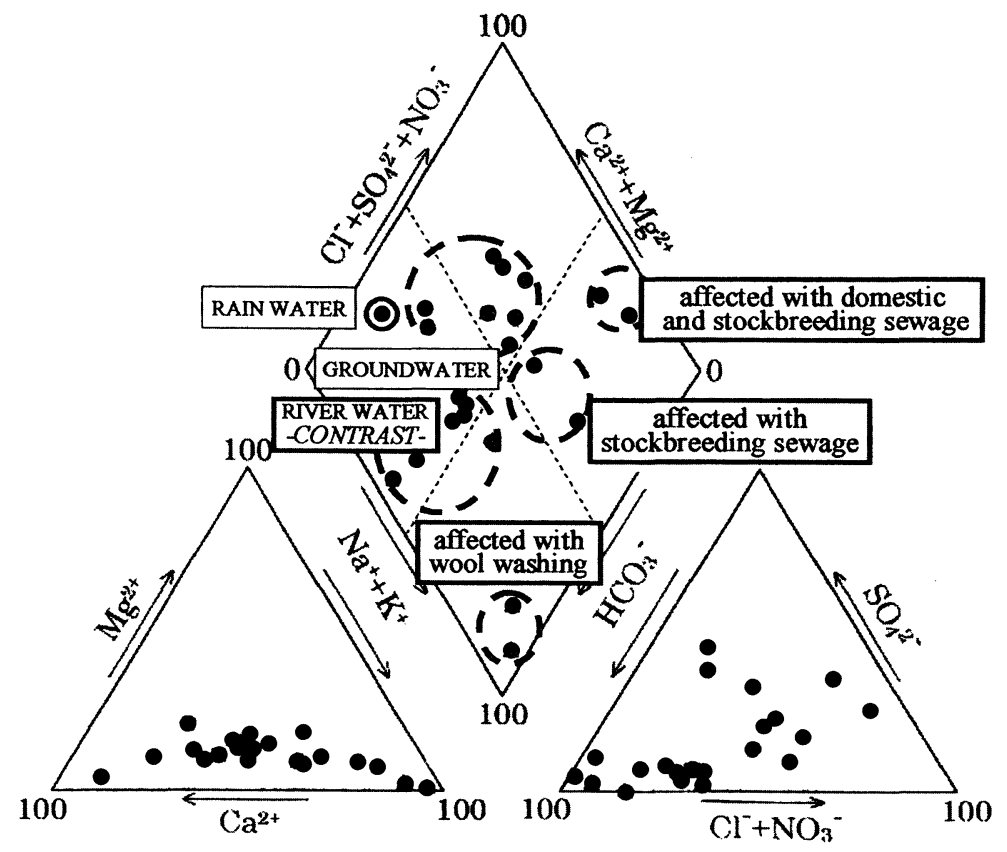

Figure 19. Triangular and key diagrams for quality of river water, including groundwater and rain water.

As shown in Figure 20, sixteen observation stations were chosen for measuring of discharge and water temperature and quality along the Muscel River. In addition, nine observation wells were also established to determine the depth to the water table from the ground surface.

As is generally pointed out, the electrical conductivity of river water has a tendency to increase in value as the water flows down. In other words, the electrical conductivity of water in the Muscel River should increase with increasing distance from its source. As is also obvious from this figure, the effect of dilution by the confluence with a tributary is clearly recognized. It is pointed out that the rather high electrical conductivity, above $1,000 \mu \mathrm{S} / \mathrm{cm}$ as observed in the upper reaches, is significantly influenced by elution from the marl which makes up the matrix of the river channel. In the lower reaches of the river in comparatively densely populated areas, human activity, including domestic sewage and livestock excrement, has a direct effect upon the quality of Muscel River.

Both the concentration and composition of eight kinds of inorganic ions in river water are also shown in Figure 20 by Stiff's hexagonal diagram. In a general way, the chemical composi- tion of water of the Muscel River is characterized by calcium sulfate, whereas the polluted water which is considerably affected by human activity is predominantly rich in sodium and chloride. As far as correlation of the river water with the surrounding groundwater is concerned, the chemical composition of river water is intimately analogous to that of the groundwater near the river channel. According to the results of measurements on the depth of the water table, river water seems to be recharged by groundwater. The strong similarity of the chemical characteristics of the water and the comparison of water levels, suggest that groundwater plays an important role as a source of the Muscel River.

\section{Conclusion and Suggestions}

\section{Cindrel Mountains (Region A)}

i) The most serious land degradation has occurred in the common lands in Jina and Poiana Sibiului on the Gornovita peneplain. The climatic conditions of Romania are semi-arid. The annual precipitation is about $600 \mathrm{~mm} / \mathrm{year}$ in the regions of the study area. Local conditions conduced to land degradation on the slopes in the mountains 


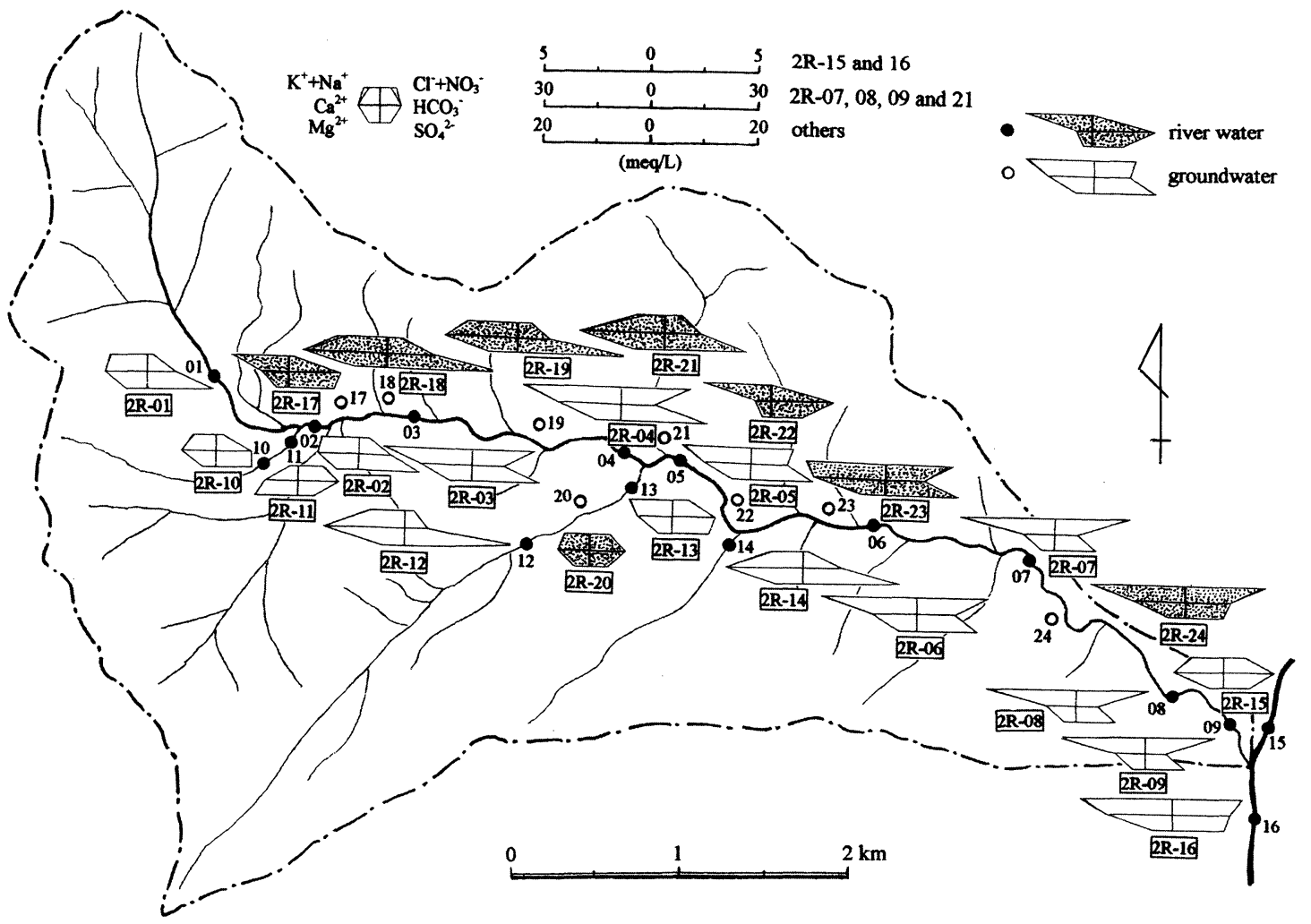

Figure 20. Distributions of dissolved constituents in river water and groundwater in the Muscel River Basin (observed on Sept. 1-3, 2004).

are evident in the region of the central part of the South Carpathian Mountains. The main reasons for this are the intense rainfall in the warmer seasons. Furthermore, the parent material of the soils is very hard rock, Precambrian crystalline schist. The weathering processes are also very slow. Parent rock exposure has increased year by year. Land degradation is serious around cattle water holes on the mountain slopes and where the tracks have gouged out tracks. The evidences of soil erosion measured from Sept. 2003 to Sept. 2004, and the results show a high-speed movement of the load.

ii) One of the other reasons for increased ecological stress is the increase in sheep numbers. This density (3-4head/ha) is now observable even at sites with poor natural conditions. It would be necessary that sheep would be managed more carefully and moved out of areas suffering serious land degradation.

iii) The washing of wool in the mountain streams by the Roma and Bayash people has caused water pollution in the villages. The sodium and potassium content of the small streams is especially high. Dangerous conditions found presently in the Cindrel Mountains. The area covered by exposed outcrops of crystalline schist is a signal of serious conditions. The shepherds in the district do not have traditional experience of such conditions. The crystalline schist is extremely hard, and its surface weathering to rebuilt soil and enable human use to occur is an extremely slow process.

iv) In the Cibin River, a striking concentration of pollutants in river water is observed at some particular points, where shored wool is washed directly in the river channel during the summer season. The concentration of dissolved substances in river water is at a maximum at the uppermost observation point, and decreases downstream. Such a peculiarity in river water quality is closely related to the location of the settlement. Pollution by animal waste is also recognized in spring water, with comparatively high 
nitrate concentrations.

\section{Pătârlagele (Region B)}

i) The production of sheep's cheese is not as large in Pătârlagele. Therefore, the stress of sheep numbers on the transhumance sites is not as strong.

ii) Geologically this area is highly prone to soil erosion, because the bedrock here is composed of soft Tertiary sedimentary rock. The weathered materials are also very thick. If the angles of the slopes are steeper than 35 degrees, even the grazing of sheep can easily cause landslides and soil erosion. It is also true, though that the thick soil layer helps the vegetation to recover quickly.

iii) In Pătârlagele, the liquid waste from cheese production is discharged onto the hilly slopes. There is no effective disposal system for this liquid waste that does not impinge on the villages.

iv) In the area of Pătârlagele, washing of wool in the creeks and on the creek banks was not observed.

v) In the Muscel River basin, a rather high concentrations of dissolved constituents in river water and groundwater was observed even in the upper reaches with no human activity. This particular water quality originates from elution from marl, which makes up the matrix of the river channel. Pollution of river water and groundwater is recognized in the lower reaches of the river basin, where water as considerably affected by human activity is predominantly rich in sodium and chloride. Contamination of river water by animal waste is also found at some observation points.

\section{Suggestions}

Cindrel Mountains (Region A). i) Strong control is needed in the common lands. In the areas where soil erosion is occurring sheep breeding should occur only over a limited timespan and over a restricted area. This is needed to facilitate the recovery of the vegetation. The first step in this process should be an improvement in the care of the grassland surface by the farmers. Technically, methods, which have been used to manage limestone outcrops in a quarries, could be usefully applied here (UrushibaraYoshino 1987).

ii) The random development of tracks of over the grassland surface should be tightly controlled. The method which has been applied in Velika Planina (Slovenia) should be introduced in this area.

iii) It is obvious that some infrastructure is needed in this area for the production of wool, but again, this needs to be much more tightly managed. For example, the process of washing wool should be controlled so that the pollution of clean water in the adjacent streams is controlled. The best contemporary techniques of wool production should be introduced to give a final product of first grade quality.

iv) National and international markets should be developed for the cheese and wool produced in the area.

v) In order to sustain a better water environment, the facts indicated above suggest a task awaiting solution, including further improvement by introduction of a sewage treatment system. In addition, the awareness of local people is also important in order to improve the present water environment.

Pătârlagele (Region B) At the sites where serious erosion has been caused by grazing, the land should be kept free of sheep for at least two or three years. In the meantime, there should be hand sowing of grass over the area to be rehabilitated. In Pătârlagele, the process of vegetation recovery will be easier than in Cindrel Mountains.

\section{Acknowledgements}

The present study was supported by Grant-in Aid for Scientific Research 2003-2005, Scientific Research (B), Head Investigator, Prof. Kazuko Urushibara-Yoshino, Project Number 15401032, of the Japanese Ministry of Education, Culture, Sports, Science and Technology. As a counter partner, Prof. Dr. Dan Balteanu, his colleagues and his graduate students, at the Institute of Geography, Academy of Romania, provided much support for the success of this research. The mayor of Jina, Mr. Iancu Beschiu provided a rain gauge observation station, and Mr. Stoica Valeriu, Mayor of Pătârlagele guided us in the field. We would like to express our pleasure at their hospitality, and our wish for sustainable development of these beautiful transhumance areas. As a cooperative researcher, Prof. Dr. Shigeru Shirasaka, Rikkyo University and Miss. Asami Hada, Graduate School of Hosei University, supported 
field work and profitable discussion.

(Received 1 September 2006)

(Accepted 15 January 2007)

\section{References}

Academia Republicii Socialiste România. 1979. Atlas: Republica Socialiste România, Institute de Geografie. Bucharesti: Editura Academiei Republicii Socialiste România.

Balteanu, D. 1983. Experimentul de teren in geomorfoligie. Bucharesti: Aplicatii la Subcarpatii Buzaului, Editura Academiei Republicii Specialiste Romania. (R)

Balteanu, D. 2003. Environmental change and sustainable development in the Romanian Carpathians. Journal of the Geographical Society of Hosei University 35: 7-12.

Balteanu, D. 2006. Case studies of land degradation in the Carpathian Mountains (Romania). In Changing social conditions and their impacts on geoecology-Transhumance regions of Romania and Slovenia. ed. K. Urushibara-Yoshino, 10-43, Tokyo: Dept. Geography, Hosei University.

Bogdan, O., Frumuselu, D., and Munteanu, I., eds. 2004. Romania soil quality and electricity transmission grid (Geographical atlas). Bucharest: Romanian Academy. (RE)

Buza, M., and Fesci, S. 1983. Cindrel -Ghid Turistic-, Colectia Muntii Nostri 28: Bucharest: Editura Sport-Turism. (R)

Lennox, I. 1996. Equipping the danube programme. Danube Watch (The Newsletter of the Environmental Programme for the Danube River Basin) 2(1): 11-12.

Mandrut, O. 2000. Geografia Romaniei. Bucharest: Ministerul Educatiei Nationale. (R)

Mori, K. 2005a. Pollution of river water and groundwater in the headwaters basin of River Cibin, the Danube River System, with special reference to their primary factor. Proc. Inst. Nat. Sci., Nihon Univ. 40: 113-119. (JE)

Mori, K. 2005b. Sheep overgrazing and water pollution -Report from Romania after the revolution (2). Geography 50(6): 88-97. (J)

Mori, K. 2006. Primary cause of water pollution in the Muscel River and the Cibin River. In Changing social conditions and their impacts on geoecology - Transhumance regions of Romania and Slovenia. ed. K. Urushibara-Yoshino, 63-75, Tokyo: Dept. Geography, Hosei University.

Mori, K., Urushibara-Yoshino, K., Balteanu, D. and Serban, M. 2006. Primary cause of water pollution in the headwaters of River Cibin, Central Romania, with special reference to sheep overgrazing. Physical Geography 27(4): 308-315.

Shirasaka, S. 2006. The transhumance of sheep in the Southern Carpathian Mt., Romania. In Changing social conditions and their impacts on geoecology - Transhumance regions of Romania and Slovenia. ed. K. Urushibara-Yoshino, 76-103, Tokyo: Dept. Geography, Hosei University.

Urushibara-Yoshino, K. 1987. Environmental changes in karst areas in Japan. Studia Carsologoca 2: 152157.

Urushibara-Yoshino, K. 2005. Sheep overgrazing and land degradation - Report from Romania after the revolution (1). Geography 50(5): 70-81. (J)

Urushibara-Yoshino, K. 2006. Case studies of soil erosion in South Carpathian Mountains. In Changing social conditions and their impacts on geoecology -Transhumance regions of Romania and Slovenia. ed. K. Urushibara-Yoshino, 53-62, Tokyo: Dept. Geography, Hosei University.

Urushibara-Yoshino, K., and Hada, A. 2005. Land degradation by intensive transhumance of sheep in Romania. Journal of the Geographical Society of Hosei University 37: 35-44. (J)

Urushibara-Yoshino, K., and Hada, A. 2006. Climatic conditions in Romania. In Changing social conditions and their impacts on geoecology - Transhumance regions of Romania and Slovenia. ed. K. Urushibara-Yoshino, 44-52, Tokyo: Dept. Geography, Hosei University.

Whitehead, C., and Noe, M. eds. 1995. Strategic action plan for the Danube River Basin 1995-2000. Vienna: Environmental Programme for the Danube River Basin.

$(\mathrm{J})$ : written in Japanese

(JE): written in Japanese with English abstract

(R): written in Romanian

(RE): written in Romanian with English abstract 